Review

\title{
Preparation and Applications of Amylose Supramolecules by Means of Phosphorylase-Catalyzed Enzymatic Polymerization
}

\section{Jun-ichi Kadokawa}

Graduate School of Science and Engineering, Kagoshima University, 1-21-40 Korimoto, Kagoshima 890-0065, Japan; E-Mail: kadokawa@eng.kagoshima-u.ac.jp

Received: 2 December 2011; in revised form: 30 December 2011 / Accepted: 7 January 2012 /

Published: 9 January 2012

\begin{abstract}
This paper reviews preparation and applications of amylose supramolecules by means of phosphorylase-catalyzed enzymatic polymerization. When the enzymatic polymerization of $\alpha$-D-glucose 1-phosphate (G-1-P) as a monomer was carried out in the presence of poly(tetrahydrofuran) (PTHF) of a hydrophobic polyether as a guest polymer, the supramolecule, i.e., an amylose-PTHF inclusion complex, was formed in the process of polymerization. Because the representation of propagation in the polymerization is similar to the way that vines of plants grow twining around rods, this polymerization method for the preparation of amylose-polymer inclusion complexes was proposed to be named "vine-twining polymerization". Various hydrophobic polyethers, polyesters, poly(ester-ether), and polycarbonates were also employed as the guest polymer in the vine-twining polymerization to produce the corresponding inclusion complexes. To obtain the inclusion complex from a strongly hydrophobic guest polymer, the parallel enzymatic polymerization system was developed as an advanced extension of the vine-twining polymerization. In addition, it was found that amylose selectively includes one side of the guest polymer from a mixture of two resemblant guest polymers, as well as a specific range in molecular weights of the guest PTHF. Amylose also exhibited selective inclusion behavior toward stereoisomers of poly(lactide)s. Moreover, the preparation of hydrogels through the formation of inclusion complexes of amylose in vine-twining polymerization was achieved.
\end{abstract}

Keywords: phosphorylase; enzymatic polymerization; amylose supramolecule; inclusion complex; vine-twining polymerization 


\section{Introduction}

Amylose is a linear natural polysaccharide with helical conformation, which is composed of glucose residues linked through $\alpha$ - $(1 \rightarrow 4)$-glycosidic linkages [1]. This is one component of starch and acts as an energy resource in nature with the other component of starch, i.e., amylopectin, which has a

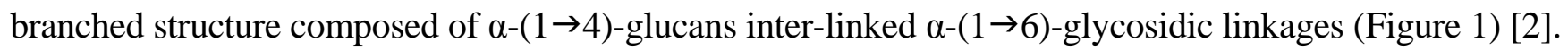
Besides having such an important role in nature, amylose is known as a high performance material because it acts as a host molecule and forms amylose supramolecules by inclusion of various guest molecules (inclusion complexes) owing to its helical conformation [3]. However, a pure amylose is currently not available from starch because the complete separation of natural amylose from amylopectin is difficult. The only method used for production of the pure amylose with the desired average molecular weight is a phosphorylase-catalyzed enzymatic polymerization [4].

Figure 1. Structures of amylose and amylopectin.

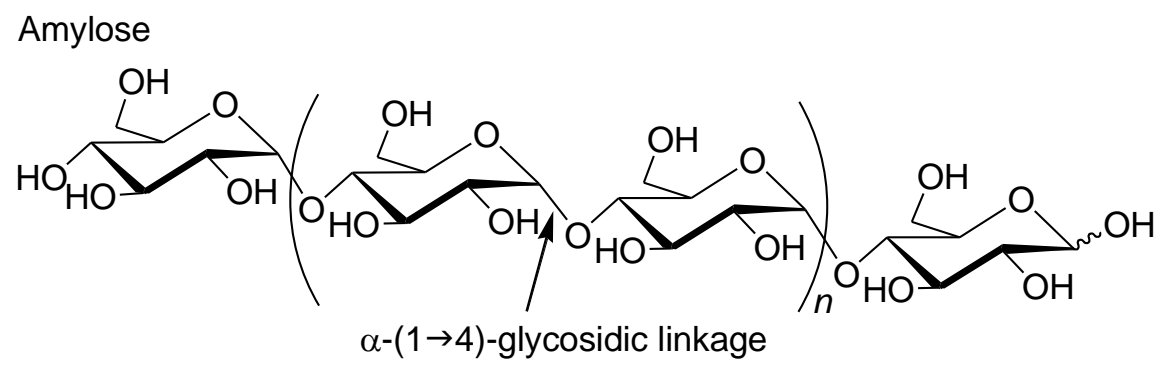

Amylopectin

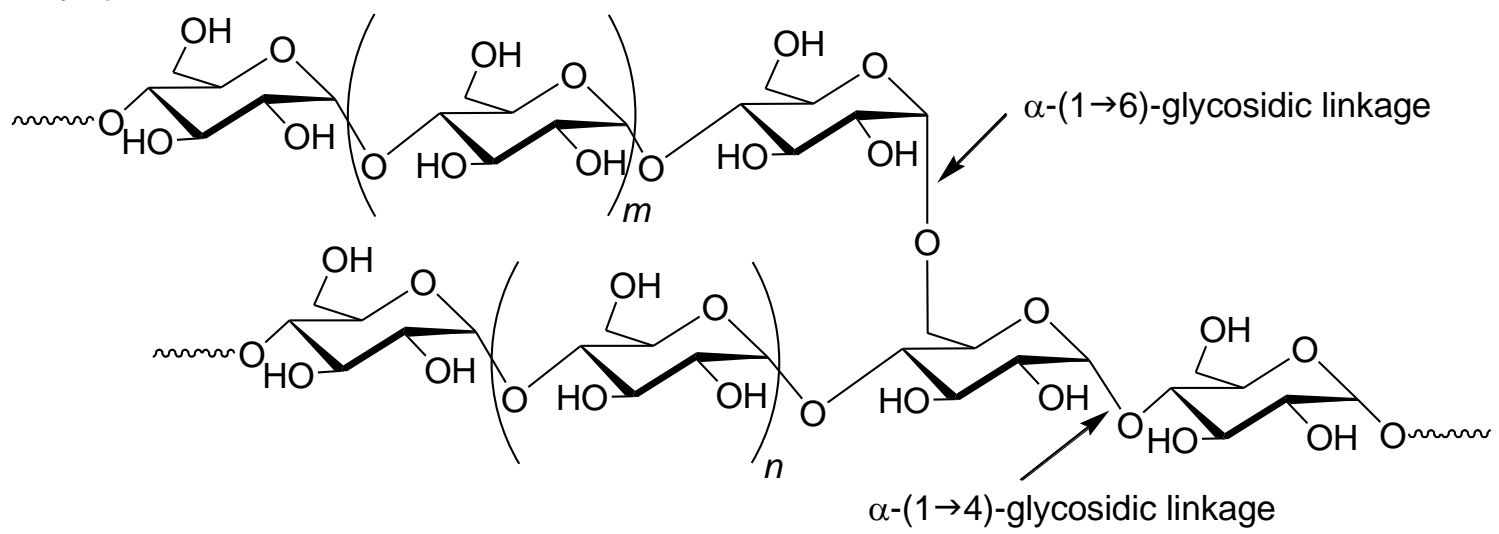

Polysaccharides are theoretically produced by the repeated glycosylations of a glycosyl donor with a glycosyl acceptor to form a glycosidic linkage [5-8]. To synthesize polysaccharides by such repeated glycosylations, the in vitro approach by enzymatic catalysis has been significantly investigated because enzymes have remarkable catalytic advantages compared with other types of catalysts in terms of the stereo- and regioselectivities [9-13]. The enzymatic glycosylation is a very powerful tool for the stereo- and regioselective construction of the glycosidic linkages under mild conditions, where a glycosyl donor and a glycosyl acceptor can be employed in their unprotected forms, leading to the direct formation of an unprotected glycoside in aqueous media $[14,15]$. Thus, repetition of the enzymatic glycosylations, i.e., enzymatic polymerization, forms polysaccharides with well-defined structure. 
Phosphorylase is an enzyme that catalyzes the reversible phosphorolytic reaction of $\alpha$ - $(1 \rightarrow 4)$-glucans, such as amylose and glycogen, at a non-reducing end in the presence of inorganic phosphate to produce $\alpha$-D-glucose 1-phosphate (G-1-P) and those with one smaller degree of polymerization (DP) [16]. Because the reaction by phosphorylase catalysis exhibits reversible nature, $\alpha-(1 \rightarrow 4)$-glycosidic linkage can be constructed by the phosphorylase-catalyzed glycosylation using G-1-P as a glycosyl donor (Figure 2). As a glycosyl acceptor, which is often called a 'primer', maltooligosaccharides with DPs higher than the smallest one recognized by phosphorylase, are used. The smallest glycosyl acceptor for the phosphorylase-catalyzed glycosylation is typically maltotetraose $\left(\mathrm{G}_{4}\right)$, whereas that for the phosphorolytic cleavage is typically maltopentaose $\left(\mathrm{G}_{5}\right)$. In the glycosylation, a glucose unit is transferred from G-1-P to a non-reducing end of the primer to form $\alpha-(1 \rightarrow 4)$-glycosidic linkage. When the excess molar ratio of G-1-P to the primer is present in the reaction system, the successive glycosylations occur as a propagation of polymerization to produce the $\alpha$ - $(1 \rightarrow 4)$-glucan chain, i.e., amylose [17-22]. Because the phosphorylase-catalyzed polymerization proceeds analogously to a living polymerization, the molecular weight of the produced amylose has a narrow distribution $\left(M_{\mathrm{w}} / M_{\mathrm{n}}<1.2\right)$ and can be controlled by the G-1-P/primer feed molar ratios [4].

Figure 2. Phosphorylase-catalyzed enzymatic polymerization.

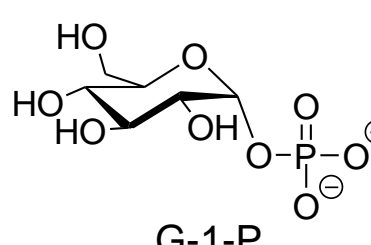

G-1-P

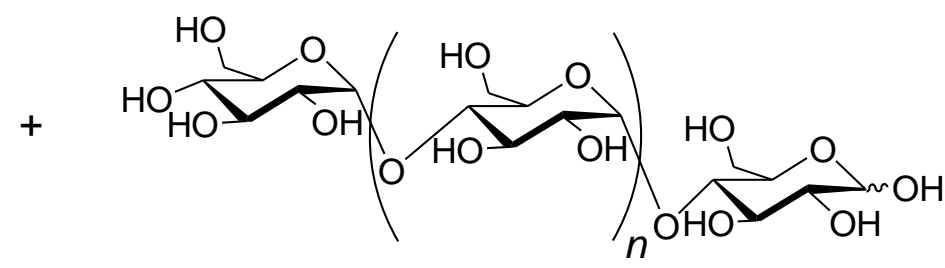

Maltooligosaccharide (Primer)
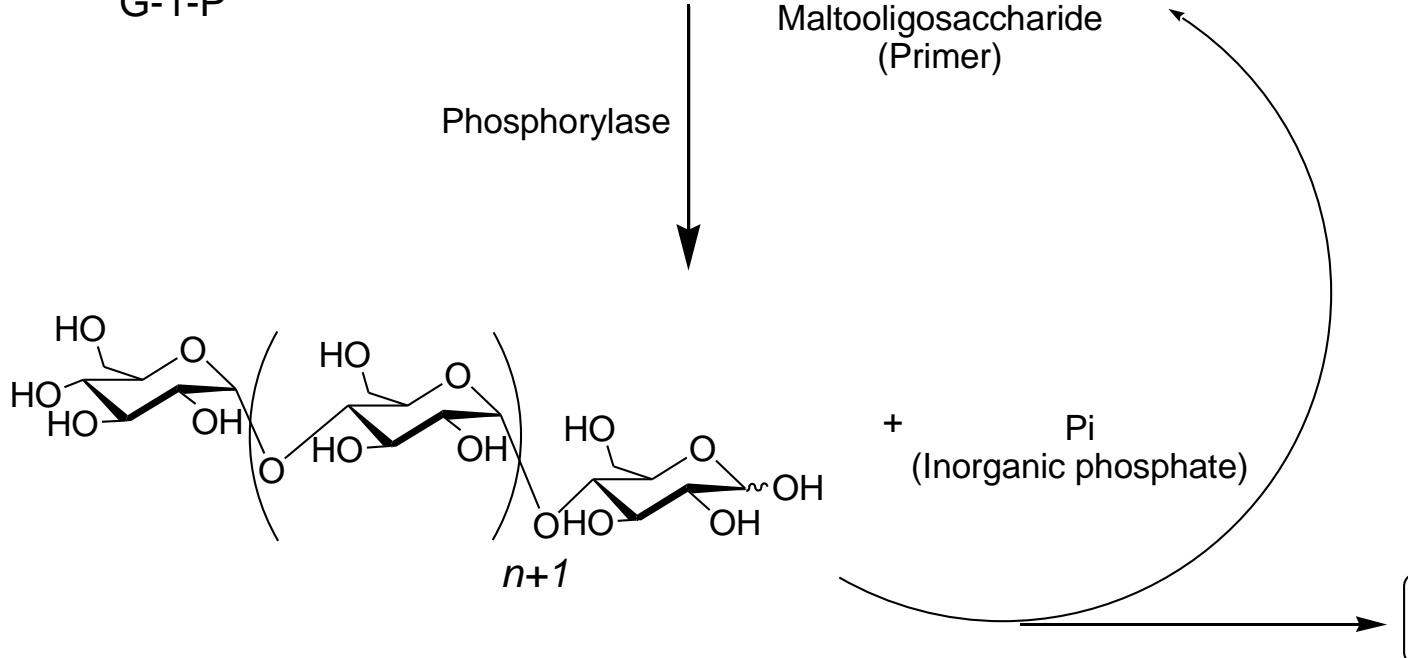

Amylose

As aforementioned, amylose is the well-known host molecule that forms inclusion complexes with guest molecules having relatively lower molecular weight. The driving force for formation of inclusion complexes is hydrophobic interaction between host and guest molecules because the cavity inside the amylose helix has hydrophobic nature due to the presence of hydrophilic hydroxy groups in the glucose units on the outer side of the helix. Therefore, hydrophobicity is required as the property of guest molecules to be included by amylose. However, only limited studies had been reported regarding the formation of inclusion complexes composed of amylose and polymeric guest molecules [23-29]. Because the driving force incorporating guest molecules into the cavity of amylose is the weak 
hydrophobic interaction, amylose does not have sufficient ability to include the long chains of polymeric guests into its cavity.

By means of the phosphorylase-catalyzed enzymatic polymerization of G-1-P for direct construction of amylose, the author's group has developed an efficient method for the preparation of inclusion complexes of amylose with synthetic polymers. The representation of propagation in the polymerization is similar as the way that vines of plants grow twining around rods. Accordingly, it has been proposed that this polymerization method for the preparation of amylose-polymer inclusion complexes is named "vine-twining polymerization" (Figure 3) [11-13,30-32]. In this review article, the author describes the principal results, discussion, and applications of vine-twining polymerization.

Figure 3. Image of "vine-twining polymerization".

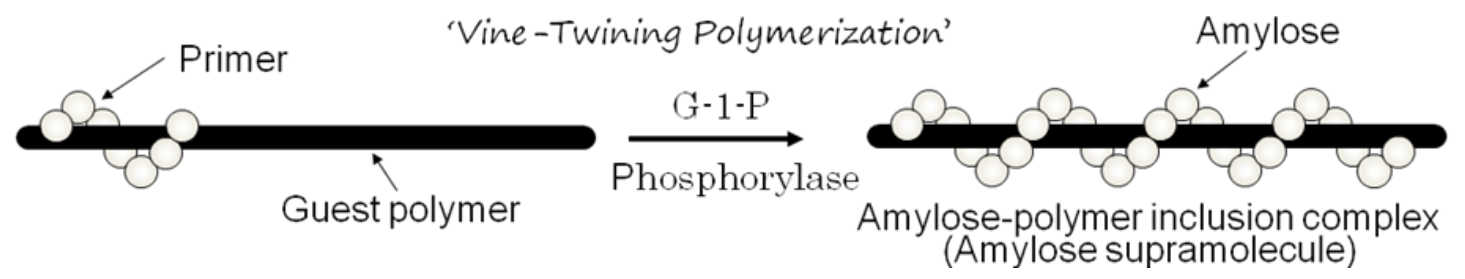

\section{Preparation, Characterization, and Formation Process of Amylose-Poly(tetrahydrofuran) Inclusion Complex by Vine-Twining Polymerization}

A first example of the vine-twining polymerization was achieved using poly(tetrahydrofuran) (PTHF) as a hydrophobic guest polyether (Figure 4) [33]. When the phosphorylase-catalyzed enzymatic polymerization of G-1-P from maltoheptaose $\left(\mathrm{G}_{7}\right)$ was performed in the presence of hydroxy-terminated telechelic PTHF with $M_{\mathrm{n}}$ of 4,000 dispersed in sodium citrate buffer, the product was gradually precipitated as the polymerization progressed, which was collected by filtration and characterized by powder X-ray diffraction (XRD) and ${ }^{1} \mathrm{H}$ NMR measurements.

The XRD profile of the product showed two strong diffraction peaks at $2 \theta=12.4$ and $19.8^{\circ}$ corresponding to $\mathrm{d}=0.71$ and $0.45 \mathrm{~nm}$, respectively (Figure 5(b)). The XRD pattern of the product was completely different from that of amylose in Figure 5(a), but similar to that of the inclusion complexes of amylose with monomeric guest molecules [34].

The ${ }^{1} \mathrm{H}$ NMR spectrum of the product in $\mathrm{NaOD} / \mathrm{D}_{2} \mathrm{O}$ (Figure 6) showed signals not only due to amylose but also due to PTHF in spite of washing with methanol, that was a good solvent of PTHF. The original PTHF was insoluble in an alkaline aqueous solution, and thus, no signals due to PTHF appeared in the ${ }^{1} \mathrm{H}$ NMR spectrum of the suspension of PTHF in $\mathrm{NaOD} / \mathrm{D}_{2} \mathrm{O}$. These NMR results indicated that the PTHF in the product was solubilized in the alkaline solution, probably because of its inclusion in the cavity of amylose. The XRD and NMR data supported the conclusion that helical inclusion complex was obtained by the vine-twining polymerization. 
Figure 4. Formation of amylase-poly(tetrahydrofuran) (PTHF) inclusion complex in phosphorylase-catalyzed polymerization in the presence of PTHF.<smiles>O=P([O-])([O-])OC1OC2OC(C1O)C(O)C(O)C2O</smiles>

G-1-P

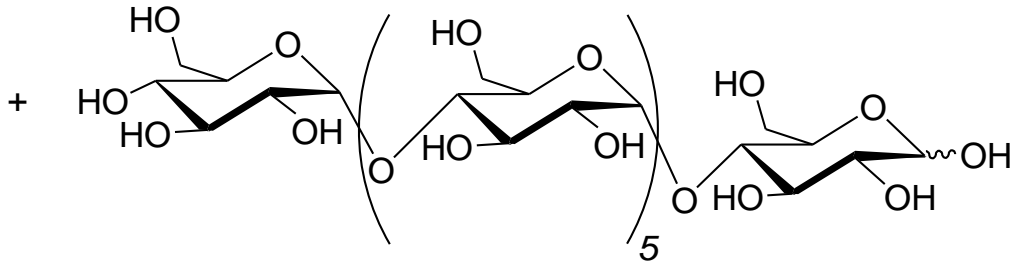

Maltoheptaose $\left(G_{7}\right)$

$+$

$\mathrm{HOCH}_{2} \mathrm{CH}_{2} \mathrm{CH}_{2} \mathrm{CH}_{2} \mathrm{OCH}_{2} \mathrm{CH}_{2} \mathrm{CH}_{2} \mathrm{CH}_{2} \mathrm{OCH}_{2} \mathrm{CH}_{2} \mathrm{CH}_{2} \mathrm{CH}_{2} \mathrm{O}$ - - OH

PTHF

Phosphorylase

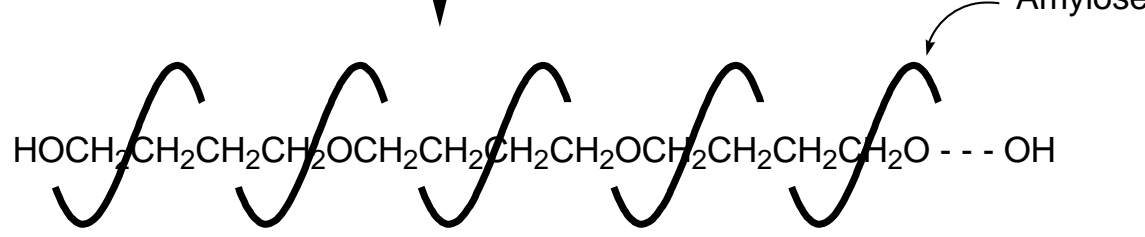

Amylose-PTHF inclusion complex

Figure 5. XRD profiles of amylose (a), amylose-PTHF inclusion complex (b), and amylose- poly(L-lactide) (PLLA) inclusion complex (c).

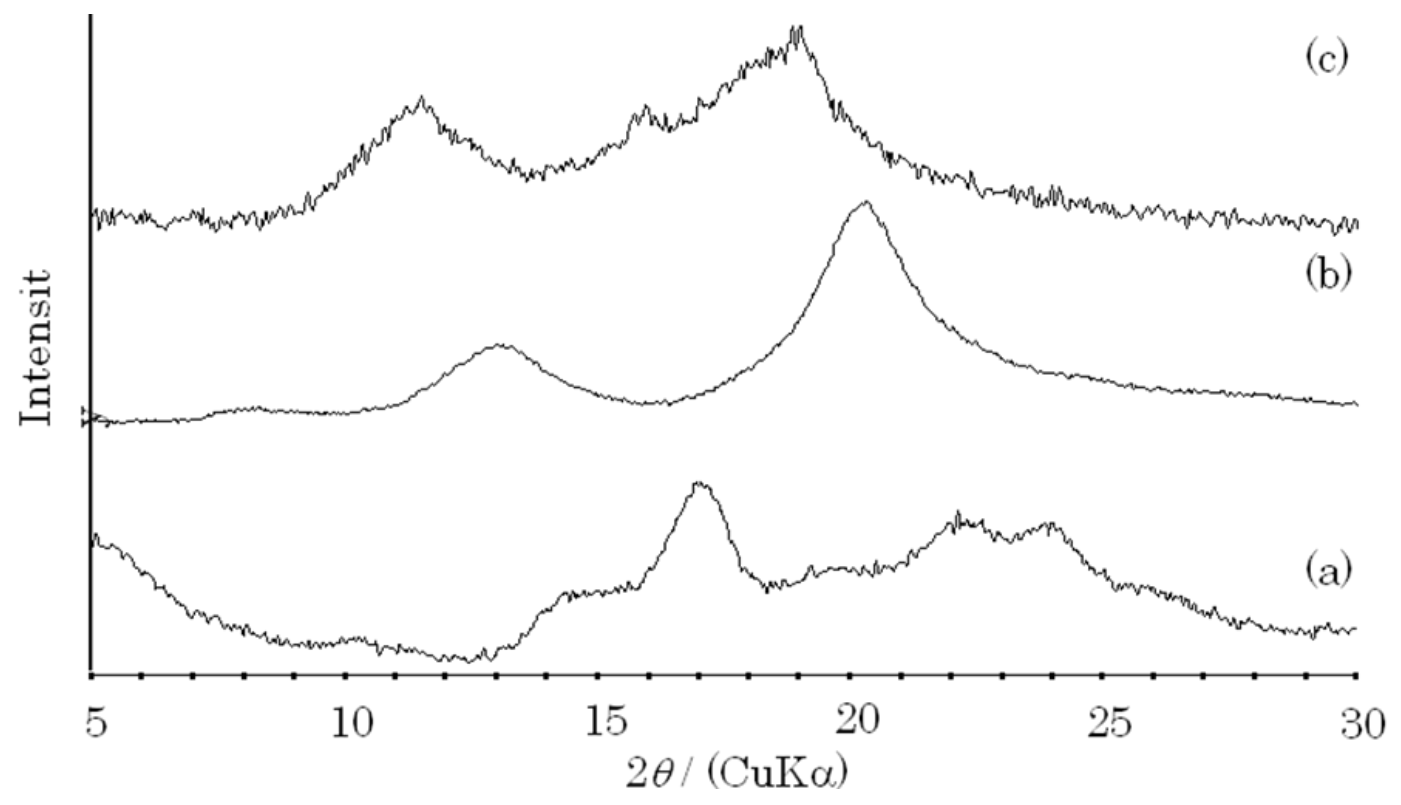


Figure 6. ${ }^{1} \mathrm{H}$ NMR spectrum of amylose-PTHF inclusion complex in $\mathrm{NaOD} / \mathrm{D}_{2} \mathrm{O}$.

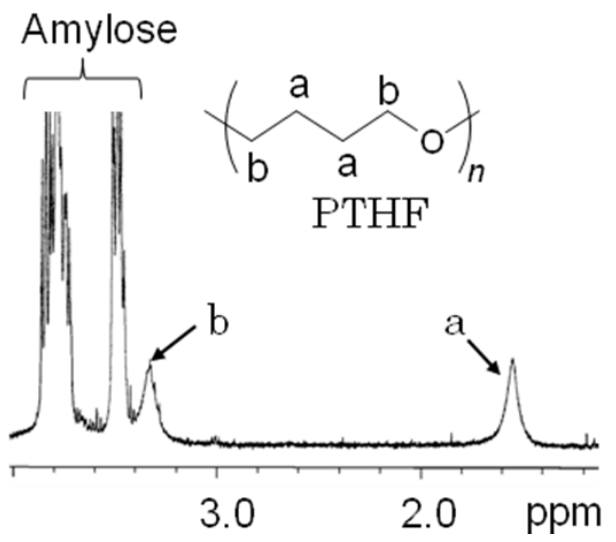

Generally, one helical turn of amylose is composed of $c a .6$ repeating glucose units when linear molecules with small sectional area are included [35]. The repeat distance of the helix of amylose was reported as $0.795 \mathrm{~nm}$, whereas the length of one unit of PTHF was calculated as $c a .0 .60 \mathrm{~nm}$. Therefore, 4.5 repeating glucose units in amylose correspond to the length of one PTHF unit. On the basis of these values, a theoretical ratio of the $\mathrm{C}-\mathrm{CH}_{2}-\mathrm{CH}_{2}-\mathrm{C}$ protons of PTHF to the anomeric $\mathrm{H} 1$ protons of the glucose units in the inclusion complex was calculated to be 0.89. Actually, the integrated ratio of the signal due to the $\mathrm{C}-\mathrm{CH}_{2}-\mathrm{CH}_{2}-\mathrm{C}$ protons to the anomeric $\mathrm{H} 1$ protons in the ${ }^{1} \mathrm{H}$ NMR spectrum of the product was in good agreement with the calculated value. This result also supported the structure of the inclusion complex.

Mixing amylose and PTHF in a buffer solvent did not induce the formation of inclusion complex. This observation strongly suggested that the inclusion complex formed during the enzymatic polymerization. Then, effects of the molecular weight and end group structure in PTHF on the formation of inclusion complexes in the vine-twining polymerization were investigated.

The formation of inclusion complexes using PTHFs with various molecular weights $(1,000,2,000$, $10,000,14,000)$ by the vine-twining polymerization was performed [36]. When PTHF with $M_{\mathrm{n}}$ of 1,000 or 2,000 was used as the guest polymer, inclusion complexes were obtained by the vine-twining polymerization. In contrast, PTHFs with higher $M_{\mathrm{n}} \mathrm{s}$ such as 10,000 and 14,000 did not form inclusion complexes with amylose by the vine-twining polymerization. The PTHFs with higher $M_{\mathrm{n}} \mathrm{s}$ were not dispersed well in buffer of the polymerization solvent, resulting in difficulty of inclusion by amylose. To obtain inclusion complexes from these PTHFs, the vine-twining polymerization was conducted in the following two-phase system. The higher molecular weight PTHF was dissolved in diethyl ether and buffer was added to the ether solution (diethyl ether:buffer $=1: 5, \mathrm{v} / \mathrm{v}$ ). Then, the phosphorylase-catalyzed enzymatic polymerization of G-1-P was carried out with vigorously stirring the mixture. Consequently, the XRD profiles of the products from both PTHFs with $M_{\mathrm{n}} \mathrm{s}$ of 10,000 and 14,000 by the two-phase system indicated the formation of the inclusion complexes.

The effect of the end groups in the telechelic PTHFs on the formation of inclusion complexes in the vine-twining polymerization was also investigated [36]. The end groups employed were the hydroxy $\left(-\mathrm{OH}\right.$, as an aforementioned standard PTHF), methoxy $\left(-\mathrm{OCH}_{3}\right)$, ethoxy $\left(-\mathrm{OCH}_{2} \mathrm{CH}_{3}\right)$, and benzyloxy $\left(-\mathrm{OCH}_{2} \mathrm{Ph}\right)$ groups. The products were characterized by the integrated ratios of the $\mathrm{C}-\mathrm{CH}_{2}-\mathrm{CH}_{2}-\mathrm{C}$ signals of PTHFs to the H1 signals of amylose in the ${ }^{1} \mathrm{H}$ NMR spectra. The ratio in the product from 
the methoxy-terminated PTHF was close to that from the hydroxy-terminated PTHF as well as the calculated value (0.89), indicating the formation of inclusion complex. In contrast, the ratio in the product from the ethoxy-terminated PTHF was much lower than the calculated value. Moreover, no inclusion complex was formed when the benzyloxy-terminated PTHF was used as the guest polymer. These results indicated that the formation of inclusion complexes was strongly affected by bulkiness of the end groups in PTHFs.

The DPs of the enzymatically synthesized amylose by phosphorylase are generally changed by the feed molar ratios of G-1-P/G 7 . The vine-twining polymerization using PTHF in lower feed molar ratio of $\mathrm{G}-1-\mathrm{P} / \mathrm{G}_{7}$ such as 10 did not yield the inclusion complex because of the production of amylose with considerably low DP, which had no helical structure. On the other hand, when the polymerization system was performed in higher feed molar ratio of $\mathrm{G}-1-\mathrm{P} / \mathrm{G}_{7}$, e.g., 1,000, the DP of amylose was not higher than $c a$. 75. In the present polymerization system, the enzymatic polymerization proceeds with forming the inclusion complex composed of amylose with V-type crystalline structure, which leads to precipitation of the product during the polymerization. The precipitation of the inclusion complex causes a difficulty in increasing the DP of amylose by the vine-twining polymerization even when the higher feed molar ratio of $\mathrm{G}-1-\mathrm{P} / \mathrm{G}_{7}$ is employed.

\section{Preparation of Inclusion Complexes by Vine-Twining Polymerization Using Other Hydrophobic} Guest Polymers

\subsection{Preparation of Inclusion Complexes Using Other Polyethers as Guest Polymers}

To investigate the effect of alkyl chain lengths in the guest polyethers on the formation of inclusion complexes in the vine-twining polymerization, the phosphorylase-catalyzed enzymatic polymerization of G-1-P was performed in the presence of polyethers with different alkyl chain lengths from PTHF (the number of methylenes $=4$ ), that is, poly (oxetane) (POXT, the number of methylenes $=3$ ) and poly(ethylene glycol) (PEG, the number of methylenes $=2$ ) [36]. The XRD pattern of the product from POXT was same as that of the amylose-PTHF inclusion complex. Furthermore, the ${ }^{1} \mathrm{H}$ NMR spectrum of the product in DMSO- $d_{6}$ showed the signals due to both amylose and POXT. These results indicated that the inclusion complex was formed by the vine-twining polymerization using POXT as the guest polyether. On the other hand, the XRD profile of the product from PEG showed the pattern for amylose, but did not show that for inclusion complex. In the ${ }^{1} \mathrm{H}$ NMR spectrum, moreover, the signals only due to amylose were observed. These analytical data indicated that amylose was produced by the enzymatic polymerization in this system, but that did not include PEG in the cavity. This was attributed to the hydrophilic nature of PEG, which caused much less hydrophobic interaction with the cavity of amylose. While the hydrophobic polyethers such as PTHF and POXT exhibited interaction with the cavity of amylose, leading to the formation of inclusion complexes by the vine-twining polymerization. The above results suggested that the hydrophobicity of guest polymers was an important factor for the formation of inclusion complexes in the vine-twining polymerization. 


\subsection{Preparation of Inclusion Complexes Using Polyesters as Guest Polymers}

On the basis of the importance in hydrophobicity of guest polymers on the formation of inclusion complexes, hydrophobic polyesters such as hydroxy-terminated telechelic poly( $\varepsilon$-caprolactone) (PCL) and poly( $\delta$-valerolactone) (PVL) were employed as the guest polymers in the vine-twining polymerization (Figure 7) [37,38]. The phosphorylase-catalyzed enzymatic polymerization of G-1-P from $\mathrm{G}_{7}$ was performed in the presence of PCL or PVL in sodium citrate buffer. The precipitated products were characterized by the ${ }^{1} \mathrm{H}$ NMR and XRD measurements. The ${ }^{1} \mathrm{H}$ NMR spectra of the products from PCL with $M_{\mathrm{n}}$ of 1,000 and PVL with $M_{\mathrm{n}}$ of 2,000 showed signals not only due to amylose but also due to the polyesters. The XRD patterns of the products were completely different from those of amylose and were similar as those of the amylose-PTHF inclusion complex. The IR measurement was also conducted to confirm the structure of the product. The IR spectrum of the original PVL exhibited a strong absorption at $1,728 \mathrm{~cm}^{-1}$, corresponding to carbonyl group of the crystalline PVL. In contrast, the carbonyl absorption of PVL in the product shifted to the region at $1,736 \mathrm{~cm}^{-1}$, which was assignable to the noncrystalline PVL. This result indicated that the crystalline PVL did not present in the product because of inclusion of a PVL chain in the cavity of amylose, suppressing the formation of crystalline aggregates. This IR observation was in good agreement with the XRD data, in which the XRD profile of a sole PVL showed strong crystalline peaks, whereas no such peaks were detected in the XRD profile of the product. All the above analytical data were taken to support the structures of the inclusion complexes.

Figure 7. Preparation of inclusion complexes by vine-twining polymerization using hydrophobic guest polyesters.
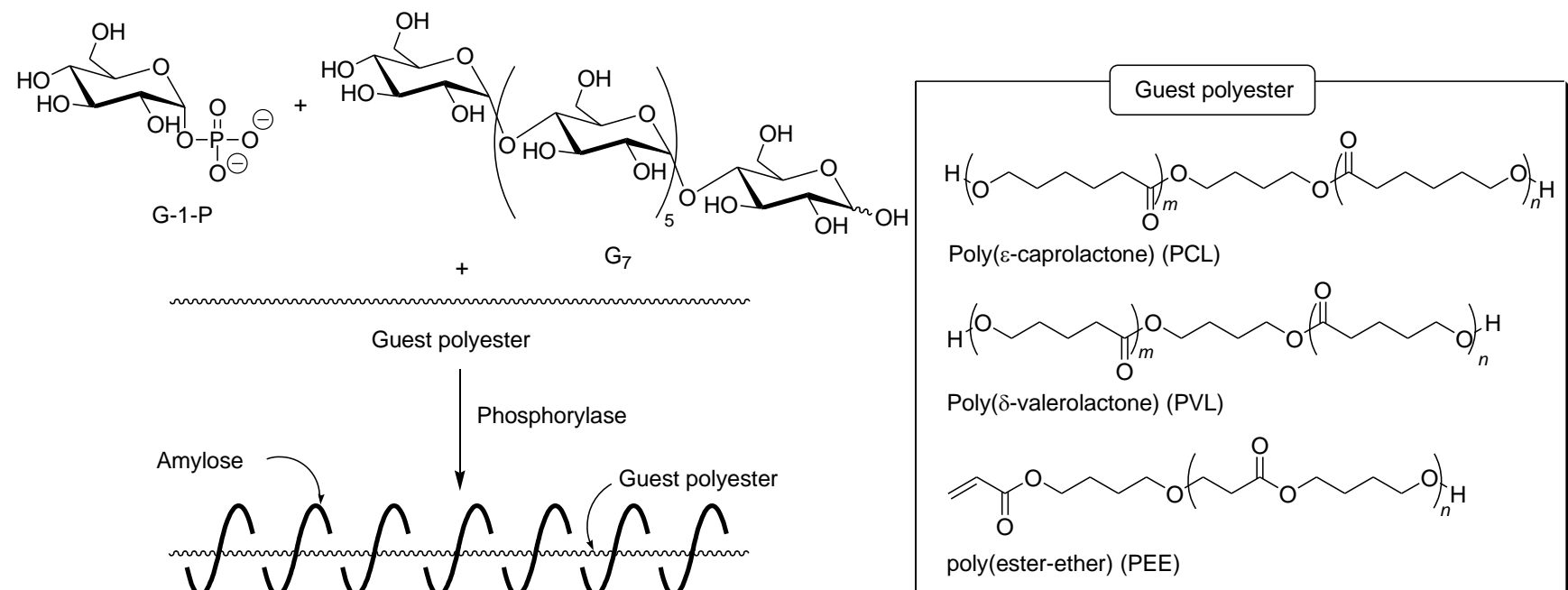

Amylose-polyester inclusion complex

Although PCL with a higher $M_{\mathrm{n}}(2,000)$ was attempted to be used as the guest polyester in the vine-twining polymerization, the PCL was not dispersed well in sodium citrate buffer of the polymerization solvent, and accordingly the inclusion complex was not formed. To obtain the inclusion complex from such PCL, the vine-twining polymerization was conducted in a mixed solvent of citrate buffer and acetone $(5: 1, \mathrm{v} / \mathrm{v})$ because the PCL was dispersed well in the mixed solvent system. The resulting product was characterized by the ${ }^{1} \mathrm{H}$ NMR and XRD measurements to be the 
inclusion complex. As aforementioned, the inclusion complex was formed from PVL with $M_{\mathrm{n}}$ of 2,000 by the vine-twining polymerization conducted in sodium citrate buffer. This suggested that PVL was more favorable as the guest polymer to form inclusion complex compared with PCL by the vine-twining polymerization.

As other guest polyester, a hydrophobic poly(ester-ether) $\left(-\mathrm{CH}_{2} \mathrm{CH}_{2} \mathrm{C}(=\mathrm{O}) \mathrm{OCH}_{2} \mathrm{CH}_{2} \mathrm{CH}_{2} \mathrm{CH}_{2} \mathrm{O}-\right.$ ), which was composed of ester and ether linkages alternatingly, was employed in the formation of an inclusion complex by the vine-twining polymerization (Figure 7) [38]. The structure of the product was confirmed by the ${ }^{1} \mathrm{H}$ NMR and XRD measurements to be the inclusion complex. When a hydrophilic poly(ester-ether) $\left(-\mathrm{CH}_{2} \mathrm{CH}_{2} \mathrm{C}(=\mathrm{O}) \mathrm{OCH}_{2} \mathrm{CH}_{2} \mathrm{O}-\right)$, which had a shorter methylene length, was used as the guest polymer, no inclusion complex was formed. This result also supported that the hydrophobicity of the guest polymers strongly affected the formation of inclusion complexes by the vine-twining polymerization.

Optically active polyesters, i.e., poly(lactide)s (PLAs), which included three kinds of the stereoisomers, i.e., poly(L-lactide) (PLLA), poly(D-lactide) (PDLA), and poly(DL-lactide) (PLDLA), were employed as the guest polyester in the vine-twining polymerization (Figure 8) [39]. First, the vine-twining polymerization using PLLA was performed by the phosphorylase-catalyzed enzymatic polymerization of G-1-P from $\mathrm{G}_{7}$. The precipitated product was characterized by the XRD and ${ }^{1} \mathrm{H}$ NMR measurements.

Figure 8. Stereoselective inclusion of amylose by vine-twining polymerization using poly(lactide)s (PLAs).

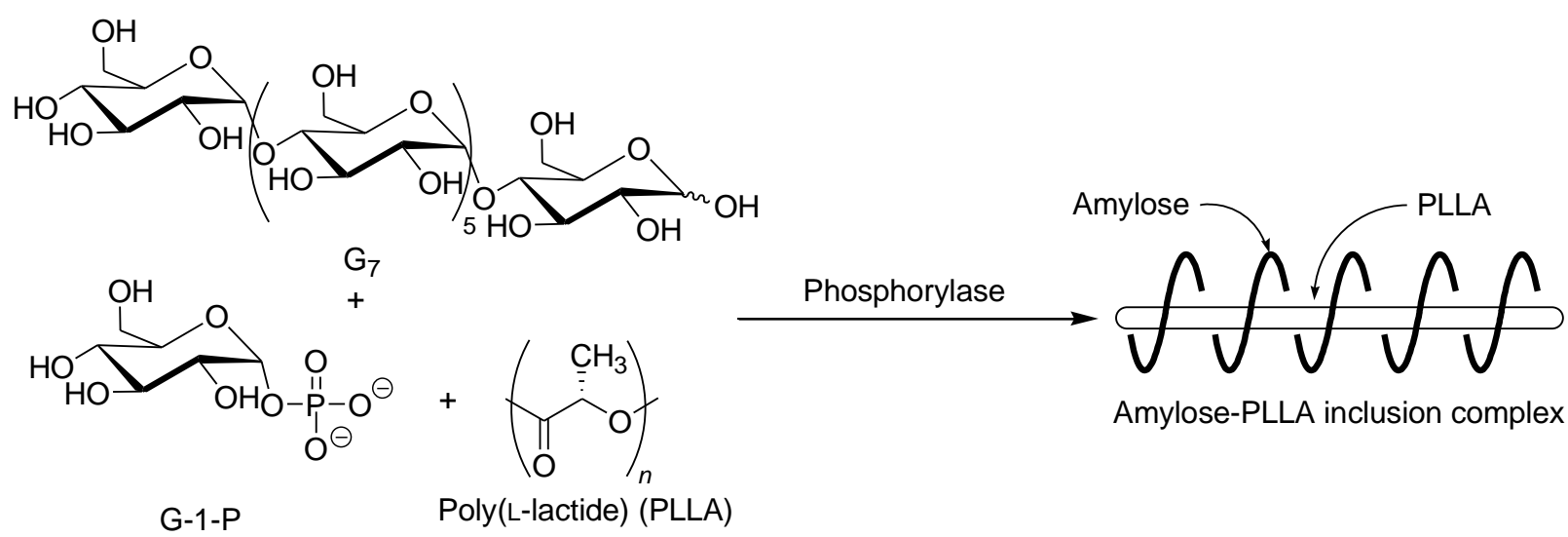

The XRD profile of the product showed two diffraction peaks at $2 \theta=11^{\circ}-12^{\circ}$ and $18^{\circ}-19^{\circ}$ (Figure 5(c)), which was completely different from that of amylose, indicating that the inclusion complex structure of the product. Interestingly, the diffraction peaks of the product appeared at lower angles compared with those of the inclusion complexes of amylose with the slender guest polymers such as PTHF (Figure 5(b)) [33]. This difference in the two XRD patterns reasonably revealed that the diameter of amylose helix in the product became larger by inclusion of the bulky PLLA in the cavity of amylose. The similar XRD pattern as that of the present product was obtained when amylose included bulky alcohols [40]. The ${ }^{1} \mathrm{H}$ NMR spectrum of the product in DMSO- $d_{6}$ showed the signals not only due to amylose but also due to PLLA. These analytical data fully supported that the 
amylose-PLLA inclusion complex was formed in the vine-twining polymerization using PLLA as the guest polyester.

To investigate the effect of the chirality in PLAs on inclusion by amylose, the vine-twining polymerization was performed using PDLA and PDLLA. Consequently, the XRD patterns of the products showed only the diffraction peaks due to amylose and the ${ }^{1} \mathrm{H}$ NMR spectra did not show the signals due to PLAs, indicating no formation of the corresponding inclusion complexes. These results indicated that amylose perfectly recognized the chirality in PLAs on the formation of inclusion complexes in vine-twining polymerization.

\subsection{Preparation of Inclusion Complexes of Amylose with Strongly Hydrophobic Polyesters in Parallel} Enzymatic Polymerization System

As aforementioned, the hydrophobicity of guest polymers is the important factor for the formation of inclusion complexes in the vine-twining polymerization. In addition to no formation of inclusion complexes from hydrophilic polymers, the production of inclusion complexes had not been achieved from polymers with strong hydrophobicity due to their aggregation in aqueous buffer solvent in the vine-twining polymerization as appeared in the case using PCL with the higher $M_{\mathrm{n}}$. As other example, the vine-twining polymerization using poly(oxepane), which was a polyether having 6 methylene units and was more hydrophobic than PTHF and POXT owing to longer alkyl chains, did not induce the formation of an inclusion complex [36].

Figure 9. Formation of inclusion complexes composed of amylose and strongly hydrophobic polyester in parallel enzymatic polymerization system.

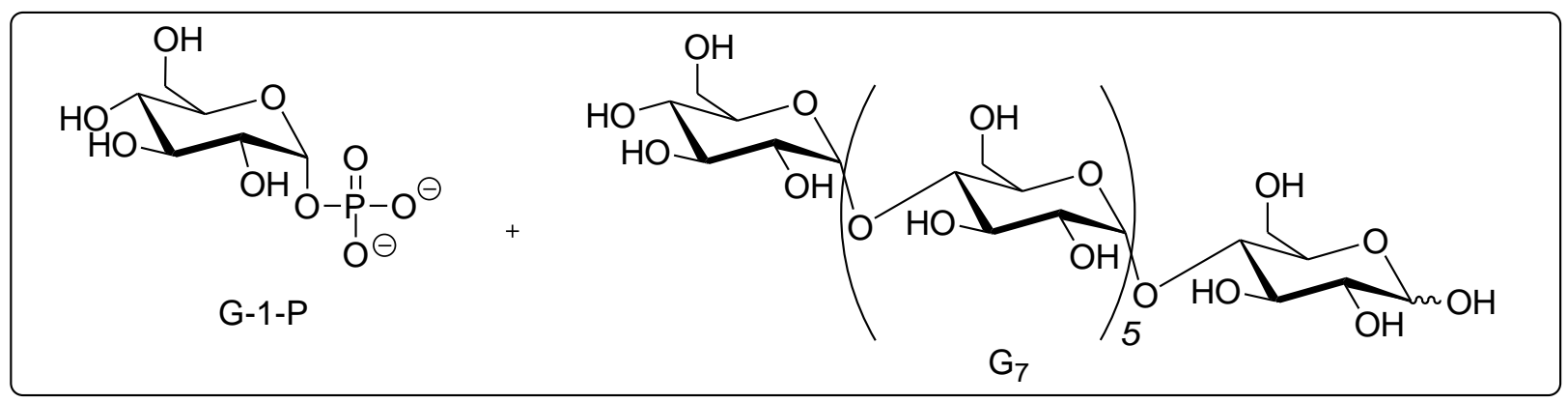

$+$

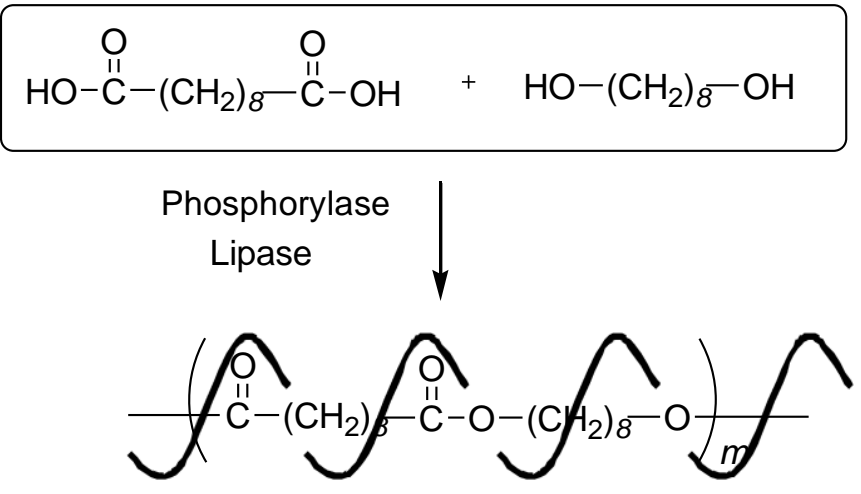

Amylose-polyester inclusion complexes 
To obtain the inclusion complex from a strongly hydrophobic polyester, a parallel enzymatic polymerization system as an advanced extension of the vine-twining polymerization was investigated (Figure 9) [41]. In this system, two enzymatic polymerizations, which were the phosphorylase-catalyzed enzymatic polymerization of G-1-P from $\mathrm{G}_{7}$, giving rise to amylose and the lipase-catalyzed polycondensation of a dicarboxylic acid and a diol, leading to an aliphatic polyester of the guest polymer $[42,43]$, were simultaneously performed. As the monomers for the latter polymerization, the dicarboxylic acid and the diol having methylene units of 8 were used, that yielded the strongly hydrophobic polyester by the lipase-catalyzed polycondensation under aqueous conditions. The product by the parallel enzymatic polymerization system was characterized by the ${ }^{1} \mathrm{H}$ NMR and XRD measurements, which indicated the formation of the inclusion complex of amylose with the polyester.

To demonstrate that the inclusion complex could be obtained only by the parallel enzymatic polymerization system, the following two experiments were carried out. When the phosphorylasecatalyzed enzymatic polymerization was performed in the presence of the polyester having methylene units of 8 , that accorded to the vine-twining polymerization manner, only amylose was produced, which did not include the polyester. As the other experiment, the lipase-catalyzed enzymatic polycondensation of the dicarboxylic acid and the diol having methylene units of 8 was carried out in the presence of amylose. Consequently, amylose included some monomers, but did not include the polyester although the enzymatic polycondensation progressed. These results of the two experiments indicated that the inclusion complex of amylose with such strongly hydrophobic polyester was formed only by the parallel enzymatic polymerization system.

\subsection{Preparation of Inclusion Complexes Using Polycarbonates as Guest Polymers}

Hydrophobic aliphatic polycarbonates were employed as the guest polymers in the vine-twining polymerization to give the corresponding inclusion complexes with amylose [44]. The four hydrophobic polycarbonates with different methylene chain lengths were used, which were poly(tetramethylene carbonate) (PC-4), poly(octamethylene carbonate) (PC-8), poly(decamethylene carbonate) (PC-10), and poly(dodecamethylene carbonate) (PC-12). First, PC-4 was employed as the guest polycarbonate in the vine-twining polymerization in an aqueous buffer/acetone mixed solvent. The precipitated product was characterized by means of the ${ }^{1} \mathrm{H}$ NMR, XRD, and IR measurements, which supported the structure of amylose-PC-4 inclusion complex.

The effect of the methylene chain lengths in the polycarbonates was investigated on the formation of inclusion complexes in this polymerization system using PC-4, PC-8, PC-10, and PC-12 as the guest polycarbonates. The ${ }^{1} \mathrm{HNMR}$ spectra of the products by the vine-twining polymerization suggested that less amounts of the polycarbonates having longer methylene chain lengths were included in the cavity of amylose. Such strongly hydrophobic polycarbonates were probably aggregated in the aqueous buffer/acetone mixed solvent, and accordingly separated from the cavity of amylose, causing difficulty in complex formation. 


\section{Selective Inclusion of Amylose in Vine-Twining Polymerization}

\subsection{Amylose Selectively Includes One from a Mixture of Two Resemblant Guest Polymers}

On the basis of the aforementioned results in the vine-twining polymerization, it can be considered that suitable hydrophobicity for properties of the guest polymers is required in deciding whether amylose includes them or not. Taking more precise information into consideration, amylose exhibits different inclusion behavior depending on subtle changes in structures of the guest polymers. Such behavior of amylose was applied to realize the selective inclusion toward two resemblant guest polymers (Figure 10) [45,46].

Figure 10. Amylose selectively includes one of two resemblant polyethers or polyesters.

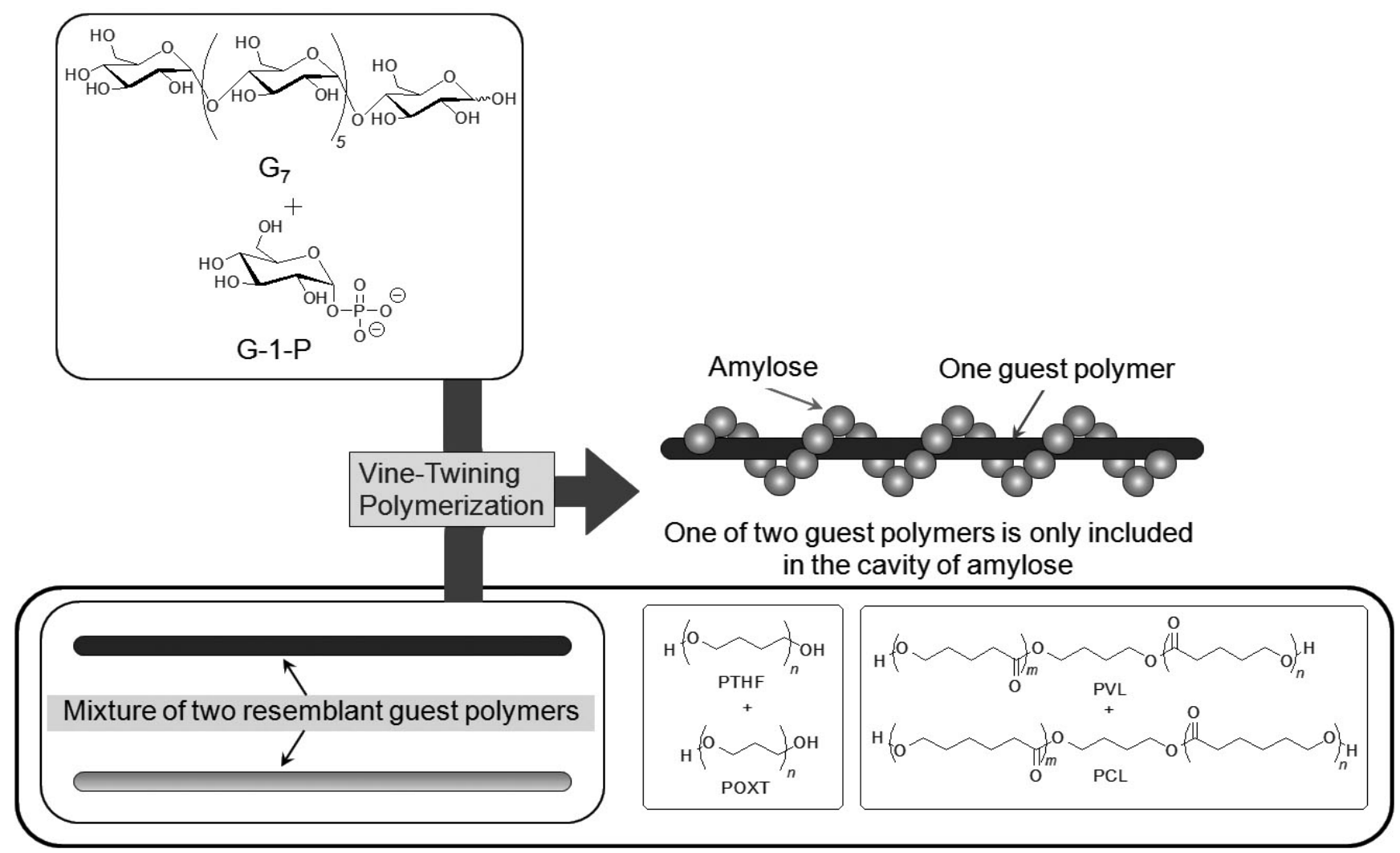

For example, the vine-twining polymerization was performed in the presence of a mixture of POXT $\left(M_{\mathrm{n}}=\sim 1,800\right)$ and PTHF $\left(M_{\mathrm{n}}=\sim 1,600\right)$ (unit molar ratio $\left.=0.90: 1.00\right)$ in sodium acetate buffer; the difference in the two polymer structures was only one methylene unit. In the ${ }^{1} \mathrm{H}$ NMR spectrum of the product (DMSO- $d_{6}$ ), the signals due to PTHF and amylose were prominently observed but the signals due to POXT were mostly not detected $(\mathrm{POXT} / \mathrm{PTHF}=0.02: 1.00)$. This NMR data indicated that amylose almost selectively included PTHF from the mixture of the two resemblant polyethers in the vine-twining polymerization $[45,46]$. The slight difference in hydrophobicities of the two polyethers probably contributed to the difference in the inclusion by amylose toward them.

The selective inclusion of amylose toward two resemblant polyesters was performed by the vine-twining polymerization in the presence of a mixture of PVL $\left(M_{\mathrm{n}}=830\right)$ and PCL $\left(M_{\mathrm{n}}=930\right)$ (unit molar ratio $=1.00: 0.92)$ under similar conditions as those described above using the polyethers [46]. In 
the ${ }^{1} \mathrm{H}$ NMR spectrum of the product (DMSO- $d_{6}$ ), the signals due to PVL and amylose were observed, whereas no signals due to PCL appeared, indicating that amylose selectively included PVL from the mixture of the two resemblant polyesters in the vine-twining polymerization.

\subsection{Amylose Selectively Includes a Specific Range of Molecular Weights in Guest Polymers}

On the basis of the above findings, the selective inclusion to a specific range in molecular weights of synthetic guest polymers by amylose was investigated in the vine-twining polymerization [47], because synthetic polymers generally have molecular weight distribution, meaning that they are reasonably considered as mixtures of analogous molecules with different numbers of the repeating units. Additionally, the numbers of repeating units contribute to exhibit different properties of the polymers with the same structure of a repeating unit. For example, PTHF with considerably low molecular weight is soluble in water although PTHF is known as a hydrophobic polymer, indicating that the hydrophobicity of PTHF is probably affected by its molecular weight. Therefore, the vine-twining polymerization in the presence of some PTHFs with different average molecular weights was examined. Three PTHFs with different $M_{\mathrm{n}} \mathrm{s}$ and $\left(M_{\mathrm{w}} / M_{\mathrm{n}}\right) \mathrm{s}\left(\mathrm{PTHF}-1 \mathrm{~K}: M_{\mathrm{n}}\right.$ and $M_{\mathrm{w}} / M_{\mathrm{n}}=1,350$ and 2.86, PTHF-3K: $M_{\mathrm{n}}$ and $M_{\mathrm{w}} / M_{\mathrm{n}}=3,040$ and 3.13, and PTHF-6K: $M_{\mathrm{n}}$ and $M_{\mathrm{w}} / M_{\mathrm{n}}=6,330$ and 2.45) were used as the guest polymers. To estimate $M_{\mathrm{n}} \mathrm{s}$ and $\left(M_{\mathrm{w}} / M_{\mathrm{n}}\right) \mathrm{s}$ of PTHFs included in the cavity of amylose, PTHFs were extracted from the inclusion complexes according to the following operation. After solutions of the inclusion complexes in DMSO were stirred at $40{ }^{\circ} \mathrm{C}$ for $13 \mathrm{~h}$, they were added to an excess amount of acetone. Then, the acetone soluble fractions were collected to obtain the guest PTHFs. The $M_{\mathrm{n}} \mathrm{s}$ and $\left(M_{\mathrm{w}} / M_{\mathrm{n}}\right) \mathrm{s}$ of the extracted PTHFs were estimated by ${ }^{1} \mathrm{H}$ NMR and GPC measurements, respectively. When PTHF-3K with $M_{\mathrm{w}} / M_{\mathrm{n}}=3.13$ was employed as the guest polymer for the vine-twining polymerization, The $M_{\mathrm{w}} / M_{\mathrm{n}}$ of PTHF included in the cavity of amylose became narrower $\left(M_{\mathrm{w}} / M_{\mathrm{n}}=1.46\right)$ although its $M_{\mathrm{n}}(=3,590)$ was almost same as that of the employed one $\left(M_{\mathrm{n}}=3,040\right)$. These results indicated that amylose selectively included a specific range in molecular weights of PTHF-3K in the vine-twining polymerization. To investigate the effect of average molecular weights of the guest PTHFs on the inclusion behavior of amylose, the vine-twining polymerization using PTHF-1K and PTHF-6K as the guest polymers was performed. Consequently, the $M_{\mathrm{n}} \mathrm{s}$ and $\left(M_{\mathrm{w}} / M_{\mathrm{n}}\right)$ s of PTHFs included in the cavity of amylose were almost the same as those using PTHF-3K as aforementioned (the included PTHF-1K: $M_{\mathrm{n}}$ and $M_{\mathrm{w}} / M_{\mathrm{n}}=3,120$ and 1.41 , the included PTHF-6K: $M_{\mathrm{n}}$ and $M_{\mathrm{w}} / M_{\mathrm{n}}=3,700$ and 1.74). Thus, it can be concluded that, in this polymerization system, amylose selectively includes a specific range in molecular weights of PTHFs.

\section{Preparation of Hydrogels through Formation of Inclusion Complexes of Amylose by Vine-Twining Polymerization}

Polymeric hydrogels are three-dimensional polymer networks including a large amount of water, which have been used in a variety of applications because of their high water contents and softness [48]. They are conventionally classified as either chemical or physical gels by the types of cross-linking points. The type of cross-linking structure often determines properties of the hydrogels. Because amylose can enzymatically be prepared and hydrolyzed by the phosphorylase and amylase catalyses, respectively [17-22,49], hydrogels with cross-linking structures based on amylose have 
a possibility for enzymatic disruption and reproduction behaviors by two enzyme-catalyzed reactions, i.e., the amylase-catalyzed hydrolysis of amylose and the formation of amylose by the phosphorylase-catalyzed polymerization.

Figure 11. Preparation of Hydrogels through Formation of Inclusion Complexes of Amylose by Vine-Twining Polymerization.
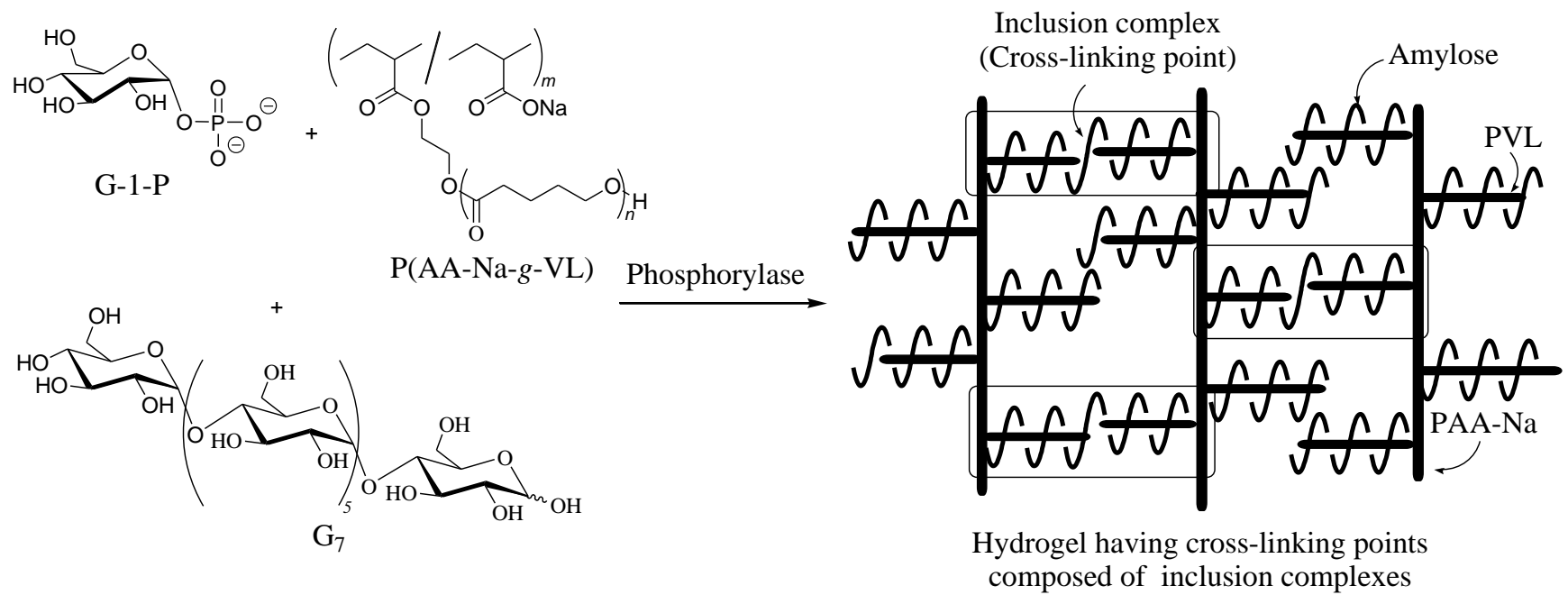

Figure 12. Cycle of enzymatic disruption and reproduction of hydrogel by two enzymatic reactions.

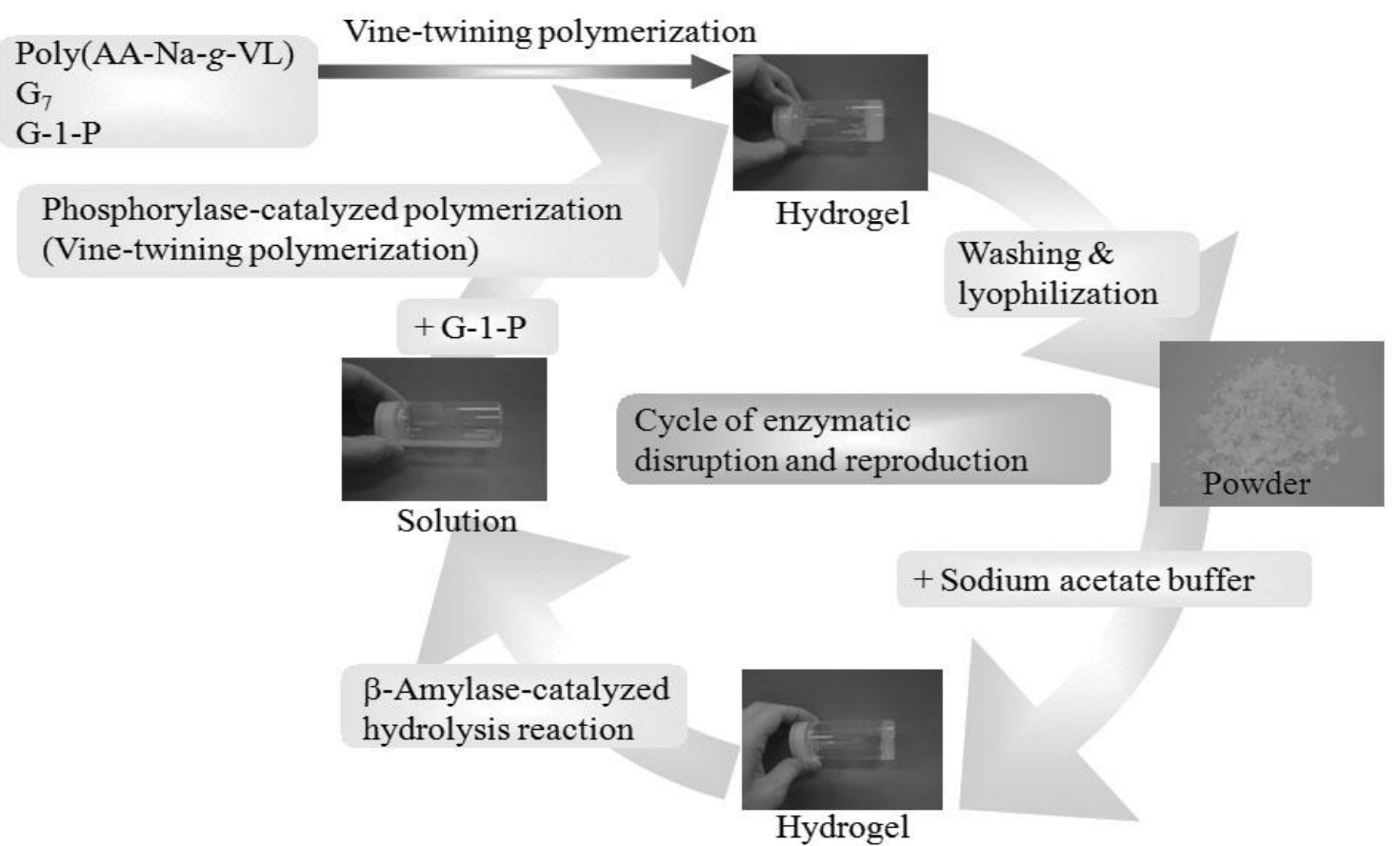

Therefore, the preparation of hydrogels through the formation of inclusion complexes of amylose in the vine-twining polymerization was investigated [50]. This was achieved by the phosphorylase-catalyzed polymerization of G-1-P from $\mathrm{G}_{7}$ in the presence of a water-soluble copolymer having the hydrophobic PVL graft chains; poly(acrylic acid sodium salt-graft- $\delta$-valerolactone) (P(AA-Na- $g$-VL)) (Figure 11). The enzymatic reaction mixture turned into a gel during the polymerization process. Because the produced amylose included the PVL graft chains in the intermolecular guest copolymers as the 
polymerization progressed, the formed inclusion complexes acted as the cross-linking points for the formation of the hydrogel. Furthermore, enzymatic disruption and reproduction of the hydrogels were achieved by the combination of the $\beta$-amylase-catalyzed hydrolysis of the amylose component and the formation of amylose by the phosphorylase-catalyzed polymerization (Figure 12). Therefore, it should be noted that the present hydrogel exhibited the enzymatically recyclable behavior by means of the two enzyme-catalyzed reactions.

\section{Conclusions}

In this review, the preparation of amylose supramolecules in the phosphorylase-catalyzed enzymatic polymerization of G-1-P, in the presence of hydrophobic polymers, such as polythers, polyesters, a poly(ester-ether), and polycarbonates according to the vine-twining polymerization manner, was overviewed. The corresponding inclusion complexes of the supramolecules were produced in the process of the polymerization. The results in the vine-twining polymerization indicated that amylose exhibited different inclusion behavior depending on subtle changes in the structures of the guest polymers. Therefore, this method was applied to the selective inclusion toward guest polymers with a subtle structural difference. Furthermore, hydrogel was produced through the formation of inclusion complexes of amylose in the vine-twining polymerization. The resulting hydrogels showed enzymatic disruption-reproduction behavior. The present method by means of the phosphorylase-catalyzed polymerization will be applied to the further production of new amylose supramolecules with well-defined structure, and the development of hierarchically controlled bio-based material in future.

\section{Acknowledgments}

The author is indebted to the co-workers, whose names are found in references from his papers, for their enthusiasistic collaborations. The author also gratefully thanks for financial supports from a Grant-in-Aid for Scientific Research from Ministry of Education, Culture, Sports, and Technology, Japan (No. 14550830, 17550118, and 19550126) and Sekisui Foundation.

\section{References}

1. Schuerch, C. Polysaccharides. In Encyclopedia of Polymer Science and Engineering, 2nd ed.; Mark, H.F., Bilkales, N., Overberger, C.G., Eds.; John Wiley \& Sons: New York, NY, USA, 1986; Volume 13, pp. 87-162.

2. Lenz, R.W. Biodegradable polymers. Adv. Polym. Sci. 1993, 107, 1-40.

3. Putseys, J.A.; Lamberts, L.; Delcour, J.A. Amylose-inclusion complexes: Formation, identity and physico-chemical properties. J. Cereal Sci. 2010, 51, 238-247.

4. Kitamura, S. Starch, Polymers, Natural and Synthetic. In The Polymeric Materials Encyclopedia, Synthesis, Properties and Applications; Salamone, C., Ed.; CRC Press: New York, NY, USA, 1996; Volume 10, pp. 7915-7922.

5. Paulsen, H. Advances in selective chemical syntheses of complex oligosaccharides. Angew. Chem. Int. Ed. Engl. 1982, 21, 155-173. 
6. Schmidt, R.R. New methods of the synthesis of glycosides and oligosaccharides-Are there alternative to the Koenigs-Knorr methods? Angew. Chem. Int. Ed. Engl. 1986, 25, 212-235.

7. Toshima, K.; Tatsuta, K. Recent progress in $O$-glycosylation methods and its application to natural products synthesis. Chem. Rev. 1993, 93, 1503-1531.

8. Mydock, L.K.; Demchenko, A.V. Mechanism of chemical $O$-glycosylation: From early studies to recent discoveries. Org. Biomol. Chem. 2010, 8, 497-510.

9. Kobayashi, S.; Uyama, H.; Kimura, S. Enzymatic polymerization. Chem. Rev. 2001, 101, 3793-3818.

10. Kobayashi, S. New development of polysaccharide synthesis via enzymatic polymerization. Proc. Jpn. Acad. Ser. B 2007, 83, 215-247.

11. Kobayashi, S.; Makino, A. Enzymatic polymer synthesis: An opportunity for green polymer chemistry. Chem. Rev. 2009, 109, 5288-5353.

12. Kadokawa, J.; Kobayashi, S. Polymer synthesis by enzymatic catalysis. Curr. Opin. Chem. Biol. 2010, 14, 145-153.

13. Kadokawa, J. Precision polysaccharide synthesis catalyzed by enzymes. Chem. Rev. 2011, 111, 4308-4345.

14. Shoda, S.; Izumi, R.; Fujita, M. Green process in glycotechnology. Bull. Chem. Soc. Jpn. 2003, $76,1-13$.

15. Seibel, J.; Jördening, H.-J.; Buchholz, K. Glycosylation with activated sugars using glycosyltransferases and transglycosidases, Biocatal. Biotranform. 2006, 24, 311-342.

16. Kitaoka, M.; Hayashi, K. Carbohydrate-processing phosphorolytic enzymes. Trends Glycosci. Glycotechnol. 2002, 14, 35-50.

17. Ziegast, G.; Pfannemüller, B. Phosphorolytic syntheses with di-, oligo- and multi-functional primers. Carbohydr. Res. 1987, 160, 185-204.

18. Gidley, M.J.; Bulpin, P.V. Aggregation of amylose in aqueous systems: The effect of chain length phase behavior and aggregation kinetics. Macromolecules 1989, 22, 341-346.

19. Niemann, C.; Sanger, W.; Pfannemüller, B.; Eigner, W.D.; Huber, A. Phospholytic Synthesis of Low-Molecular-Weight Amyloses with Modified Terminal Groups; Comparison of Potato Phosphorylase Andmuscle Phosphorylase b. In ACS Symposium Series; Comstock, M.J., Ed.; American Chemical Society: Washington, DC, USA, 1991; pp. 189-204.

20. Fujii, K.; Takata, H.; Yanase, M.; Terada, Y.; Ohdan, K.; Takaha, T.; Okada, S.; Kuriki, T. Bioengineering and application of novel glucose polymers. Biocatal. Biotransform. 2003, 21, $167-172$.

21. Yanase, M.; Takaha, T.; Kuriki, T. $\alpha$-Glucan phosphorylase and its use in carbohydrate engineering. J. Food Agric. 2006, 86, 1631-1635.

22. Ohdan, K.; Fujii, K.; Yanase, M.; Takaha, T.; Kuriki, T. Enzymatic synthesis of amylose. Biocatal. Biotransform. 2006, 24, 77-81.

23. Shogren, R.L.; Greene, R.V.; Wu, Y.V. Complexes of starch polysaccharides and poly(ethylene-co-acrylic acid) - structure and stability in solution. J. Appl. Polym. Sci. 1991, 42, 1701-1709.

24. Shogren, R.L. Complexes of starch with telechelic poly( $\varepsilon$-caprolactone) phosphate. Carbohydr. Polym. 1993, 22, 93-98. 
25. Ikeda, M.; Furusho, Y.; Okoshi, K.; Tanahara, S.; Maeda, K.; Nishino, S.; Mori, T.; Yashima, E. A luminescent poly(phenylenevinylene)-amylose composite with supramolecular liquid crystallinity. Angew. Chem. Int. Ed. 2006, 45, 6491-6495.

26. Kida, T.; Minabe, T.; Okabe, S.; Akashi, M. Partially-methylated amyloses as effective hosts for inclusion complex formation with polymeric guests. Chem. Commun. 2007, doi: 10.1039/B616231B.

27. Kida, T.; Minabe, T.; Nakano, S.; Akashi, M. Fabrication of novel multilayered thin films based on inclusion complex formation between amylose derivatives and guest polymers. Langmuir $\mathbf{2 0 0 8}$, 24, 9227-9229.

28. Frampton, M.J.; Claridge, T.D.W.; Latini, G.; Brovelli, S.; Cacialli, F.; Anderson, L. Amylosewrapped luminescent conjugated polymers. Chem. Commun. 2008, doi: 10.1039/B803335H.

29. Kaneko, Y.; Kyutoku, T.; Shimomura, N.; Kadokawa, J. Formation of amylose-poly(tetrahydrofuran) inclusion complexes in ionic liquid media. Chem. Lett. 2011, 40, 31-33.

30. Kaneko, Y.; Kadokawa, J. Vine-twining polymerization: A new preparation method for well-defined supramolecules composed of amylose and synthetic polymers. Chem. Rec. 2005, 5, 36-46.

31. Kaneko, Y.; Kadokawa, J. Synthesis of nanostructured bio-related materials by hybridization of synthetic polymers with polysaccharides or saccharide residues. J. Biomater. Sci. Polym. Ed. 2006, 17, 1269-1284.

32. Kaneko, Y.; Kadokawa, J. Modern Trends in Macromolecular Chemistry; Lee, J.N., Ed.; Nova Science Publishers, Inc.: Hauppauge, NY, USA, 2009; Chapter 8, pp. 199-217.

33. Kadokawa, J.; Kaneko, Y.; Tagaya, H.; Chiba, K. Synthesis of an amylose-polymer inclusion complex by enzymatic polymerization of glucose 1-phosphate catalyzed by phosphorylase enzyme in the presence of polyTHF: A new method for synthesis of polymer-polymer inclusion complexes. Chem. Commun. 2001, doi: 10.1039/B008180I.

34. Seneviratne, H.D.; Biliaderis, C.G. Action of $\alpha$-amylases on amylose-lipid complex superstructures. J. Cereal Sci. 1991, 13, 129-143.

35. Zobel, H.F. Starch crystal transformations and their industrial importance. Starch 1988, 40, 1-7.

36. Kadokawa, J.; Kaneko, Y.; Nagase, S.; Takahashi, T.; Tagaya, H. Vine-twining polymerization: Amylose twines around polyethers to form amylose-polyether inclusion complexes. Chem. Eur. J. 2002, 8, 3321-3326.

37. Kadokawa, J.; Kaneko, Y.; Nakaya, A.; Tagaya, H. Formation of an amylose-polyester inclusion complex by means of phosphorylase-catalyzed enzymatic polymerization of $\alpha$-D-glucose 1-phosphate monomer in the presence of poly(E-caprolactone). Macromolecules 2001, 34, 6536-6528.

38. Kadokawa, J.; Nakaya, A.; Kaneko, Y.; Tagaya, H. Preparation of inclusion complexes between amylose and ester-containing polymers by means of vine-twining polymerization. Macromol. Chem. Phys. 2003, 204, 1451-1457.

39. Kaneko, Y.; Ueno, K.; Yui, T.; Nakahara, K.; Kadokawa, J. Amylose's recognition of chirality in polylactides on formation of inclusion complexes in vine-twining polymerization. Macromol. Biosci. 2011, 11, 1407-1415.

40. Yamashita, Y. Single crystals of amylose V complexes. II. Crystals with 71 helical configuration. J. Polym. Sci. Part A-2 1966, 4, 161-171. 
41. Kaneko, Y.; Saito, Y.; Nakaya, A.; Kadokawa, J.; Tagaya, H. Preparation of inclusion complexes composed of amylose and strongly hydrophobic polyesters in parallel enzymatic polymerization system. Macromolecules 2008, 41, 5665-5670.

42. Kobayashi, S.; Uyama, H.; Suda, S.; Namekawa, S. Dehydration polymerization in aqueous medium catalyzed by lipase. Chem. Lett. 1997, doi: 10.1246/cl.1997.105.

43. Suda, S.; Uyama, H.; Kobayashi, S. Dehydration polycondensation in water for synthesis of polyesters by lipase catalyst. Proc. Jpn. Acad. Ser. B 1999, 75, 201-206.

44. Kaneko, Y.; Beppu, K.; Kadokawa, J. Preparation of amylose/polycarbonate inclusion complexes by means of vine-twining polymerization. Macromol. Chem. Phys. 2008, 209, 1037-1042.

45. Kaneko, Y.; Beppu, K.; Kadokawa, J. Amylose selectively includes one from a mixture of two resemblant polyethers in vine-twining polymerization. Biomacromolecules 2007, 8, 2983-2985.

46. Kaneko, Y.; Beppu, K.; Kyutoku, T.; Kadokawa, J. Selectivity and priority on inclusion of amylose toward guest polyethers and polyesters in vine-twining polymerization. Polym. J. 2009, 41, 279-286.

47. Kaneko, Y.; Beppu, K.; Kadokawa, J. Amylose selectively includes a specific range of molecular weights in poly(tetrahydrofuran)s in vine-twining polymerization. Polym. J. 2009, 41, 792-796.

48. Lee, K.Y.; Mooney, D.J. Hydrogels for tissue engineering. Chem. Rev. 2001, 101, 1869-1879.

49. Bijttebier, A.; Goesaert, H.; Delcour, J.A. Amylase action pattern on starch polymers. Biologia 2008, 63, 989-999.

50. Kaneko, Y.; Fujisaki, K.; Kyutoku, T.; Furukawa, H.; Kadokawa, J. Preparation of enzymatically recyclable hydrogels through the formation of inclusion complexes of amylose in a vine-twining polymerization. Chem. Asian J. 2010, 5, 1627-1633.

(C) 2012 by the authors; licensee MDPI, Basel, Switzerland. This article is an open access article distributed under the terms and conditions of the Creative Commons Attribution license (http://creativecommons.org/licenses/by/3.0/). 